\title{
Epidemiology of traumatic cardiac arrest in patients presenting to emergency department at a level 1 trauma center
}

\author{
Sanjeev Bhoi, Prakash Ranjan Mishra, Kapil Dev Soni ${ }^{1}$, Upendra Baitha, Tej Prakash Sinha
}

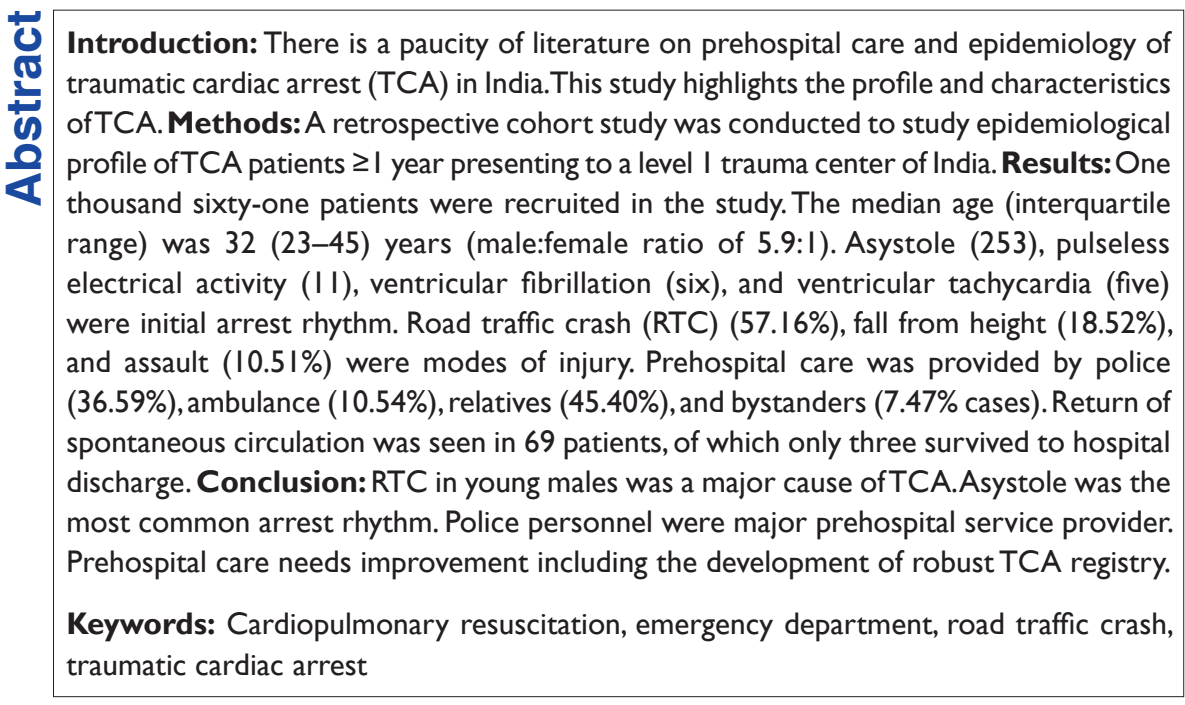

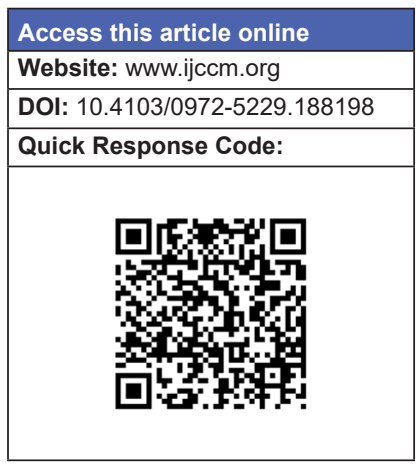

\section{Introduction}

Trauma is a leading cause of death and disability globally. The World Health Organization (WHO) global status report on road safety 2015 shows that over 1.2 million people die each year due to road traffic crash (RTC) with prolonged morbidity in millions. ${ }^{[1]}$

Deaths due to trauma have increased by $62.9 \%$ in 2014 as compared to 2004 in India as per the National Crime Records Bureau (NCRB). ${ }^{[2]}$ Prehospital and emergency care are in their infancy in India. ${ }^{[3]}$ There is a paucity of literature on prehospital care, emergency care, and

\section{From:}

Departments of Emergency Medicine and ${ }^{1}$ Anaesthesia and Critical Care,

Jai Prakash Narayan Apex Trauma Centre, All India Institute of Medical

Sciences, New Delhi, India

\section{Correspondence:}

Dr. Sanjeev Bhoi, Department of Emergency Medicine, Jai Prakash Narayan

Apex Trauma Centre, All India Institute of Medical Sciences,

New Delhi - 110 029, India.

E-mail: sanjeevbhoi@gmail.com epidemiology of traumatic cardiac arrest (TCA). Hence, the present study has tried to highlight the profile and characteristics of TCA patients presenting to emergency department (ED) of a level 1 trauma center of India.

\section{Methods}

A retrospective single-centered cohort study was conducted between 2008 and 2013 in the ED of a level 1 trauma center of India, which has an annual ED visit of 50,000-60,000 patients. Patients with TCA received acute

This is an open access article distributed under the terms of the Creative Commons Attribution-NonCommercial-ShareAlike 3.0 License, which allows others to remix, tweak, and build upon the work non-commercially, as long as the author is credited and the new creations are licensed under the identical terms.

For reprints contact: reprints@medknow.com

How to cite this article: Bhoi S, Mishra PR, Soni KD, Baitha U, Sinha TP. Epidemiology of traumatic cardiac arrest in patients presenting to emergency department at a level 1 trauma center. Indian J Crit Care Med 2016;20:469-72. 
care as per the advanced cardiac life support guidelines. Details of TCA patients arriving to ED were retrieved from paper-based registers and computerized patient record system. It represented patients above 1 year of age, of either sex who had an out-of-hospital or inhospital (ED) TCA. Patients $<1$ year in rigor mortis or decapitated were excluded from the study. Data mining was carried out by feeding in password-protected Microsoft Excel sheets. The epidemiological variables studied were age, sex, mechanism of injury, prehospital care and transportation, primary arrest rhythms, and outcome in terms of death or discharge from the hospital. The data were analyzed using Stata (version 11.2, STATA CORP, Texas, U.S.A) software. Ethics approval was taken for the study from the concerned ethics committee.

\section{Results}

About 0.3 million trauma victims presented to the ED of the trauma center from 2008 to 2014 [Figure 1]. Of these, $1061(0.36 \%)$ presented with TCA who provided cardiopulmonary resuscitation (CPR) and recruited in the study. A total of $992(93.5 \%)$ patients had out-of-hospital cardiac arrest (OHCA) and 40 had cardiac arrest in ED. Data regarding location of cardiac arrest were not available in 29 patients. A total of 909 patients $(85.67 \%)$ were males and $152(14.33 \%)$ were females (male:female ratio being 5.9:1). The majority were in the age group of 19-64 years with median age of 32 years (interquartile range [IQR] 23-45). The details of age and gender are shown in Table 1.

Mechanism of injury was available in 872 patients. RTC was seen in 571 (57.16\%), fall from height in 185 (18.52\%), and assault in $105(10.51 \%)$ patients. The remaining 200 patients had other modes of injury (railway track,

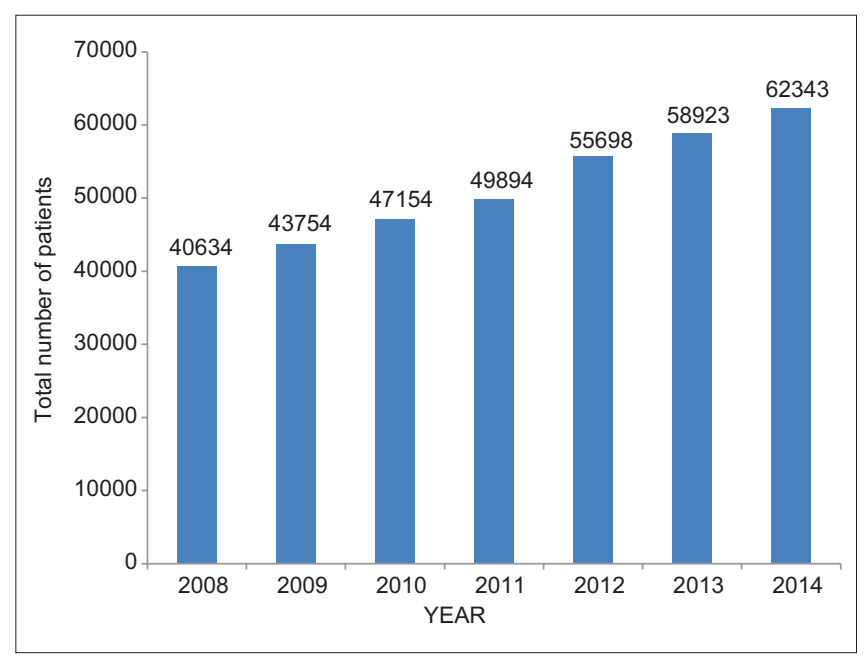

Figure I: Annual burden of trauma patients in the emergency department gunshot, drowning, electrocution, self-harm, etc.). Data about initial arrest rhythm were available in 275 patients. Asystole in 253, pulseless electrical activity (PEA) in 11, ventricular fibrillation (VF) in 6 and ventricular tachycardia (VT) in 5 patients were observed [Table 2]. Data regarding prehospital care and transportation were available in 1044 patients. It was provided by police personnel in 382 (36.59\%), ambulance personnel in $110(10.54 \%)$, relatives in $474(45.40 \%)$, and bystanders in $78(7.47 \%)$ patients [Table 2]. Data about bystander CPR were not available.

Data regarding return of spontaneous circulation (ROSC) after the first attempt of CPR were available in 933 patients. ROSC was present in $69(7.4 \%)$, and $864(92.60 \%)$ patients could not be revived [Table 3]. In

Table I: Age and sex distribution in patients with traumatic cardiac arrest $(n=106 \mathrm{I})$

\begin{tabular}{lccc}
\hline $\begin{array}{l}\text { Age } \\
\text { group (years) }\end{array}$ & Male, $\boldsymbol{n}(\%)$ & Female, $\boldsymbol{n}(\%)$ & Total, $\boldsymbol{n}(\%)$ \\
\hline$\leq 18$ & $95(10.45)$ & $47(30.92)$ & $142(13.38)$ \\
$19-64$ & $738(81.19)$ & $92(60.53)$ & $830(78.23)$ \\
$\geq 65$ & $76(8.36)$ & $13(8.55)$ & $89(8.39)$ \\
Total & $909(85.67)$ & $152(14.33)$ & $106 \mid$ \\
\hline
\end{tabular}

Table 2: Initial arrest rhythms, prehospital care, and transportation

\begin{tabular}{lc}
\hline & $n(\%)$ \\
\hline Initial arrest rhythms $(n=275)$ & $253(92)$ \\
Asystole & $11(4)$ \\
PEA & $6(2.18)$ \\
VF & $5(1.82)$ \\
VT & \\
Prehospital care and transportation $(n=1044)$ & $382(36.59)$ \\
Police personnel & $110(10.54)$ \\
Ambulances & $474(45.40)$ \\
Relatives & $78(7.47)$ \\
By-standers &
\end{tabular}

PEA: Pulseless electrical activity; VT: Ventricular tachycardia; VF: Ventricular fibrillation

Table 3: Outcome of cardiopulmonary resuscitation in traumatic cardiac arrest patients

\begin{tabular}{lcc}
\hline & Declared dead, $\boldsymbol{n}(\%)$ & ROSC, $\boldsymbol{n}(\%)$ \\
\hline Age group (years) $(n=933)$ & $119(12.75)$ & \\
$\leq 18$ & $671(71.92)$ & $53(1.18)$ \\
$19-64$ & $74(7.93)$ & $5(0.68)$ \\
$\geq 65$ & & \\
Sex $(n=933)$ & $741(79.42)$ & $60(6.43)$ \\
$\quad$ Male & $123(13.18)$ & $9(0.97)$ \\
$\quad$ Female & & \\
Mode of injury $(n=872)$ & $463(53.10)$ & $39(4.47)$ \\
RTC & $66(7.57)$ & $9(1.03)$ \\
Assault & $164(18.81)$ & $9(1.03)$ \\
Fall from height & II8 (I3.53) \\
$\quad$ Others & $4(0.46)$ \\
\hline n: Total number; ROSC: Return of spontaneous circulation; RTC: Road traffic crash
\end{tabular}


patients with ROSC, five survived beyond $24 \mathrm{~h}$, but only three patients survived to hospital discharge.

\section{Discussion}

The burden of trauma in India is increasing as per the NCRB. ${ }^{[2]}$ Despite this increase, the outcome of resuscitative efforts is still very poor as highlighted in the present study.

Emergency care in India is in its infancy. Prehospital care in the National Capital Region is poor. Prehospital transportation services are run by the government ambulances, private ambulances, and police without any coordination among them. ${ }^{[3]}$ Ambulances are often used as merely transport vehicle with limited or nontrained personals manning the ambulances. The absence of trained paramedics allows unskilled labor to attempt life-saving tasks. Most of the trauma victims do not achieve access to medical care within $1 \mathrm{~h}$.

The present study shows that police personnel were major prehospital service providers. About $36.59 \%$ of total patients were picked and transported by them to the hospital. Although they played a valuable role in patient transportation, they provided minimal prehospital care. This is because police personnel in India are usually untrained in providing CPR and basic emergency care (BEC).

Husain and Eisenberg concluded that providing the police officers with basic CPR skills and training in the use of automated external defibrillator can increase survival rates for OHCAs (major link of "early defibrillation" in the "chain of survival"). ${ }^{[4]}$ Hence, there is an immediate need for training of police personnel and paramedics in BEC in India. The authors have taken initiatives in this regard, and the All India Institute of Medical Sciences BEC course was designed to address the issue. ${ }^{[5]}$ They have trained medical and nonmedical personnel, including paramedics, police, and paramilitary forces in BEC. Allison et al. developed and tested an undergraduate prehospital trauma course in 205 medical students of $4^{\text {th }}$ year of medical school. ${ }^{[6]}$ The feedback was positive and they all felt better equipped to deal with the emergency situations in the future. The authors recommend the training in basic prehospital care for laypersons including school children and medical professionals in India.

ROSC was achieved in $7.4 \%$ cases on the first attempt at CPR in our study. There has been a debate on CPR in traumatic OHCA patients citing its futility, wastage of resources and time. Battistella et al. in their study concluded that trauma victims who are pulseless and have asystole or heart rate $<40$ beats/min should be declared dead at the scene of injury. ${ }^{[7]}$ Deasy et al. reported a bystander CPR rate of $10.2 \%$ with on-scene ROSC rate of $15.4 \%$ in traumatic OHCA. ${ }^{[8]}$ Leis et al. after analyzing about 167 TCA cases found that ROSC was obtained in $49.1 \%$, and $6.6 \%$ cases achieved a complete neurological recovery. ${ }^{[9]}$ The high rate of ROSC in the above study was attributed to advanced life support (ALS) on-scene, which included intubation, intravenous access, fluid and drug therapy, point-of-care blood analysis, and procedures such as chest drain insertion, pericardiocentesis, and focused assessment with sonography for trauma. Hence, the authors support the view that CPR efforts in trauma-associated OHCA patients are not futile and if supplemented by ALS on scene, may result in increased survival and neurological outcome.

The initial rhythms were asystole in 253, PEA in 11, VF in six, and VT in five patients. Previous studies have identified shockable (VT/VF) or nonshockable (asystole/ PEA) rhythm on presentation as the most important factor for an increased chance of survival from OHCA and have concluded that patients with VF or VT had 5-10 times increased chances of survival. ${ }^{[10]}$

About $78.23 \%$ patients in our study were in the age group of 19-64 years. The median patient age was 32 years (IQR 23-45). Deasy et al. found that the median age of traumatic OHCA patients was 36 years (IQR 25-55). ${ }^{[8]}$ The WHO statistics also supports this trend of young, productive working population being lost each year due to RTC. ${ }^{[1]}$ Male preponderance $(85.67 \%)$ in our study is comparable with Deasy et al., which reported $77.5 \%$ of males in traumatic OHCA patients. ${ }^{[8]}$ This may be explained by the fact that the major working population outdoors are males who are predisposed to traumatic injury risk factors. RTC was the most common mode of injury seen in $57.16 \%$ patients. This is in accordance with the data from NCRB, India, published in 2014. ${ }^{[2]}$ India accounts for as high as 6\% of the world's RTC although it has just $1 \%$ of the world's vehicles. The RTC rate of 35 per 1000 vehicles in India is one of the highest in the world. Hence, the authors stress the need for mass education of public regarding injury prevention strategies.

\section{Limitations}

The bulk of retrospective data was retrieved from paper-based registers. Since cardiac arrest is a terminal event, doctors and paramedics are not enthusiastic and 
do not stress upon complete documentation of events. This accounts for missing and incomplete patient data. Hence, the authors stress the need for electronic recording of data and TCA registry.

\section{Conclusion}

RTC in young males is a major cause of TCA. Asystole was the predominant initial rhythm. ROSC was achieved in $7.4 \%$ cases with hospital to discharge in three patients.

\section{Financial support and sponsorship}

Nil.

\section{Conflicts of interest}

There are no conflicts of interest.

\section{References}

1. World Health Organization. Global Status Report on Road Safety; 2015. Available from: http://www.who.int/violence_injury_prevention/ road_safety_status/2015/en/.[Last accessed on 2015 Oct 25 ].
2. National Crimes Records Bureau. Accidental Deaths and Suicides in India 2014. New Delhi: Ministry of Home Affairs, Government of India; 2014. Available from: http://www.ncrb.gov.in. [Last accessed on 2015 Oct 25].

3. Das AK, Gupta SB, Joshi SR, Aggarwal P, Murmu LR, Bhoi S, et al. White paper on academic emergency medicine in India: INDO-US Joint Working Group (JWG). J Assoc Physicians India 2008;56:789-98.

4. Husain S, Eisenberg M. Police AED programs: A systematic review and meta-analysis. Resuscitation 2013;84:1184-91.

5. Bhoi S, Thakur N, Chauhan S, Kumar R, Aggarwal D, Gulati V, et al. (A24) Does community emergency care initiative improves the knowledge, skill, and attitude of healtheare workers and laypersons in basic emergency care in India? Prehosp Disaster Med 2011;26:s7-8.

6. Allison KP, Kilner T, Porter KM, Thurgood A. Pre-hospital care - The evolution of a course for undergraduates. Resuscitation 2002;52:187-91.

7. Battistella FD, Nugent W, Owings JT, Anderson JT. Field triage of the pulseless trauma patient. Arch Surg 1999;134:742-5.

8. Deasy C, Bray J, Smith K, Hall D, Morrison C, Bernard SA, et al. Paediatric traumatic out-of-hospital cardiac arrests in Melbourne, Australia. Resuscitation 2012;83:471-5.

9. Leis CC, Hernández CC, Blaneo MJ, Paterna PC, Hernández Rde E, Torres EC. Traumatic cardiac arrest: Should advanced life support be initiated? J Trauma Acute Care Surg 2013;74:634-8.

10. Herlitz J, Engdahl J, Svensson L, Angquist KA, Young M, Holmberg S. Factors associated with an increased chance of survival among patients suffering from an out-of-hospital cardiac arrest in a national perspective in Sweden. Am Heart J 2005;149:61-6. 